\title{
Problemas Derivados del Uso de Internet y el Teléfono Móvil en Estudiantes Universitarios
}

\author{
Daniel Garrote-Rojas ${ }^{(1)_{*}}$, Sara Jiménez-Fernández ${ }^{(2)}$ e Isabel $\mathbf{M}^{\mathrm{a}}$. Gómez-Barreto ${ }^{(1)}$ \\ (1) Dpto. de Pedagogía, Facultad de Educación del Campus de Albacete, Universidad de Castilla-La \\ Mancha, Edif. Simón Abril, Plaza La Universidad, 3, 02071 Albacete, España \\ (e-mail: daniel.garrote@uclm.es; isabelmaria.gomez@uclm.es) \\ (2) Unidad de Salud Mental Infanto-Juvenil del Complejo Hospitalario de Jaén, Carretera Bailén-Motril s/n, \\ 23009 Jaén, España (e-mail: sarajimenezfer@hotmail.com)
}

* Autor a quien debe ser dirigida la correspondencia

Recibido Ago. 5, 2017; Aceptado Oct. 13, 2017; Versión final Nov. 30, 2017, Publicado Abr. 2018

\begin{abstract}
Resumen
Se realiza un estudio para conocer el tiempo que dedican los universitarios a las nuevas tecnologías diaria y semanalmente e identificar si su uso se convierte en un problema. La muestra se diferencia entre alumnos universitarios de primer y cuarto curso de la Facultad de Educación de Albacete, en España. Para realizar este estudio descriptivo se ha utilizado el Cuestionario sobre Uso Problemático de Nuevas Tecnologías (UPNT). Los resultados indican que los estudiantes dedican un tiempo elevado al uso del teléfono móvil y de internet y que un alto porcentaje de ellos tienen problemas por este motivo. Los estudiantes más jóvenes presentaron un uso mayor de internet frente a los estudiantes de curso más avanzado. En el uso del teléfono móvil no se aprecia estas diferencias. Como conclusión, se debe indicar que más de la mitad de la muestra dedica más de cinco horas al día al teléfono móvil y que el $79,6 \%$ de la misma manifiesta haber tenido problemas secundarios de comportamiento por su uso excesivo.
\end{abstract}

Palabras clave: TIC; uso de nuevas tecnologías; estudiantes universitarios; uso de internet; abuso del teléfono móvil

\section{Problems Derived from the use of Internet and Mobile Phone in University Students}

\begin{abstract}
A study aimed to know the time, daily and weekly, that university students dedicate to the use of new technologies and to identify if its use becomes a problem in any sense. The sample is differentiated between university students of first and fourth year of the Faculty of Education of Albacete, in Spain. To carry out this descriptive study, the Questionnaire on Difficult Use of New Technologies (UPNT) has been used. The results indicate that students spend a lot of time on the use of the mobile phone and internet and that a high percentage of them have some problems for this reason. Younger students had a greater use of the Internet than the more advanced students. In the use of the mobile phone these differences are not appreciated. As a conclusion, it should be pointed out that more than half of the students dedicate more than five hours a day to the mobile phone. Also, $79.6 \%$ of these users indicate that they have had secondary behavioral problems due to its excessive use.
\end{abstract}

Keywords: ICT; use of new technologies; internet use; mobile phone; abuse mobile phones 


\section{INTRODUCCIÓN}

El uso de las Tecnologías de la Información y de la Comunicación (TIC) está creciendo a un ritmo acelerado y está dando lugar a cambios importantes en la sociedad, permitiendo que la información esté al alcance de todos y ofreciendo nuevos canales de comunicación y de entretenimiento. Estas herramientas introducen nuevas vías de relación entre personas capaces de mejorar su calidad de vida y que resultan relevantes en la empresa, la docencia o la sanidad, entre otros.

El teléfono móvil, gracias a su conexión a internet (Smartphone), ha pasado a ser un objeto donde se almacena todo tipo de información y se dispone de múltiples aplicaciones que dan respuesta a los gustos y necesidades de su propietario. Por lo tanto, internet hizo que su funcionalidad sea muy amplia. Los mayores consumidores de las TIC son los jóvenes (Winocur, 2006). Con respecto al uso de internet son los jóvenes los que mejor se mueven entre el mundo real y el virtual (Cruces, Guil, Sánchez y Pereira, 2016). Según la fundación Pfizer (2009), el uso de internet en jóvenes de entre 11 y 20 años es del 98\%. Devine y Lloyd (2012) observan que las redes sociales se han convertido en el medio preferido de comunicación. Sin embargo, el $31 \%$ de la población menor de dieciocho años reconoce utilizar internet sin un objetivo claro, el $12 \%$ tiene la necesidad permanente de estar en conexión, el 16\% se molesta cuando tiene que dejar de usar internet y el $40 \%$ presenta señales de consumos prolongados (Garmendia, Garitaonandia, Martínez y Casado, 2011). Romero, Carrió y Yang (2016) indican un uso de más de cuatro horas diarias de internet para el $56 \%$ de la muestra de estudiantes universitarios. Estos datos nos llevan a querer adentrarnos en estudiar cómo es la situación en el uso y respuesta a las TIC por parte de los jóvenes universitarios. Los problemas procedentes del uso de internet parecen no superar el 10\% (Muñoz-Rivas, Fernández, y Gámez-Guadix, 2010; Carbonell, Fúster, Chamarro y Oberst, 2012). Sin embargo, los sujetos presentan deseos de permanecer conectados, refieren sentimientos de culpa, falsifican el tiempo que dedican a internet cuando se les pregunta, presentan cambios en sus hábitos de salud y disminuyen el tiempo dedicado al descanso (Young, 1998; Gracia, Vigo, Fernández y Marcó, 2002; Muñoz-Rivas, Fernández, y Gámez-Guadix, 2010) y experimentan una pérdida de autoestima (Wang, Wu, Chang y Chuang, 2013).

En individuos con tendencia solitaria pueden aparecer cambios comportamentales que consisten en establecer una interacción en línea en sustitución del cara a cara (Caplan, 2003; Chung, 2013) como el síndrome de Hikikomori, donde los jóvenes permanecen recluidos de forma voluntaria por elementos personales o sociales. El uso inapropiado de las TIC por los jóvenes en edad escolar puede tener conductas de riesgo (Castellana, Sánchez-Carbonell, Graner y Beranuy, 2007; Garaigordobil, 2011) como el acceso a contenidos inapropiados, la pérdida de intimidad, el grooming (conductas realizadas por adultos para ganar la confianza de menores de edad mediante un vínculo emocional con fines sexuales) y el bullying. Además, las TIC pueden acarrear también importantes riesgos emocionales y sociales en los adolescentes (Marciales y Cabra, 2011). La ciberadicción puede llegar a ser una patología que genere dependencia en quien la padezca (Echeburría y Corral, 2010). Los síntomas de alerta de una adicción a las Nuevas Tecnologías (NT) son: la pérdida de control del consumo, el cambio en el estilo de vida y la dependencia psicológica (Cruces, Guil, Sánchez y Pereira, 2016). A pesar de la descripción del problema y del reconocimiento entre la comunidad científica, todavía no se ha producido un consenso sobre los criterios para incluirlo en el Manual Diagnóstico y Estadístico de los Trastornos Mentales (DSM). En la última versión, DSM-V (2013), únicamente se recoge la adicción en el juego patológico. Sin embargo, la adicción a las NT se daría cuando hay una búsqueda y uso compulsivo de los recursos tecnológicos que afecta a la calidad de vida, pudiendo darse un síndrome de abstinencia o malestar emocional sino se pueden hacer uso de la misma (Echeburría y Corral, 2010).

Los recursos tecnológicos han modificado la forma de comunicación en las aulas. Existen diferentes metodologías (Flipped Classroom, Blended-Learning, entre otras) que usan distintos tipos de dispositivos móviles (teléfonos o tabletas). Estos dispositivos podemos utilizarlos junto con internet para dar una mayor respuesta a la gran variedad de aplicaciones existentes, para permitir el acceso a los recursos educativos necesarios como son archivos, enlaces web o plataformas moodle, y para facilitar la información a aquellos estudiantes que tengan dificultades en la movilidad. Otra ventaja de los dispositivos digitales está en su uso como herramienta en el trabajo activo-colaborativo, permitiéndoles el desarrollo de la competencia digital o la competencia interpersonal a través del trabajo colaborativo.

Con esta investigación pretendemos, como objetivo general, describir el tiempo que dedican diaria y semanalmente los universitarios al teléfono móvil y a internet. Como objetivos específicos:

(i) Analizar las características del uso de internet y el teléfono móvil entre estudiantes de primer y cuarto curso.

(ii) Conocer los problemas asociados al uso excesivo de las TIC.

(iii) Describir los patrones de consumo entre la población de primer y de cuarto curso del Grado de Maestro en Educación. 


\section{MÉTODOLOGÍA}

El trabajo de investigación realizado ha sido de corte cuantitativo a través de la aplicación de un cuestionario. El análisis de los datos fue descriptivo, por medio de medidas de tendencia central y de dispersión. Tras comprobar que las variables siguen una distribución normal (Test de Kolmogorov-Smirnov) se llevó a cabo una comparación de medias independientes (ANOVA) de cada uno de los diferentes ítems que hacen referencia al uso de internet y el teléfono móvil entre los universitarios de primer y cuarto curso. Para el análisis estadístico se ha utilizado el programa Statisfical Package for the Social Science (SPSS) versión 22.0.

\section{Diseño y participantes}

Esta investigación es de corte transversal y carácter descriptivo. Han participado 108 estudiantes universitarios pertenecientes a la Universidad de Castilla-La Mancha. El 51.85\% pertenecen al primer curso y el $48.15 \%$ a cuarto curso, la media de edad de toda la muestra es de $20.94 \pm 3.38$, donde el $94.4 \%$ son mujeres y el $5.6 \%$ varones. Para la recogida de la información se ha utilizado el cuestionario de Uso Problemático de Nuevas Tecnologías (UPNT). Obteniendo el consentimiento informado por parte de los participantes para llevar a cabo la investigación.

\section{Variables e instrumentos}

El cuestionario UPNT (Labrador, Villadandos, Crespo y Becoña, 2013) está formado por 41 ítems. Integra cuatro subescalas relacionadas con el uso de Internet, los videojuegos, el teléfono móvil y el uso de la Televisión. Los tres primeros ítems de cada subescala se refieren al lugar de uso y el tiempo dedicado diaria y semanalmente. El resto de factores de cada subescala pretenden identificar las características de las conductas problemáticas, si se miente en el uso de las mismas, si su uso produce relax o no y en la capacidad de dejar de usarlas sin que aparezcan sentimientos negativos. El tipo de respuesta es tipo Likert, que varía en función de cada ítems, entre "nunca", "a veces", "con frecuencia" y "siempre"; y en otras ocasiones "nunca", "alguna vez al mes", "alguna vez a la semana" y "todos los días". Como índices de fiabilidad, alfa de Cronbach, es de 0.876. Presentando una adecuada validez en el ámbito clínico.

\section{RESULTADOS Y DISCUSIÓN}

En la investigación participaron 108 estudiantes, 56 de primer curso (51.85\%) y $52(48.15 \%)$ de cuarto curso. La edad media global fue de $20.94 \pm 3.38$, en el primer curso la media fue de $20.00 \pm 3.33$ y en cuarto curso fue de $21.96 \pm 3.16$. El $5,6 \%(n=6)$ de la muestra fueron varones y el $94,4 \%(n=102)$ mujeres. Sobre el uso de las NT se encontró que internet fue utilizado por el $100 \%$ de los estudiantes y que $99,1 \%$ accedía a diario. El teléfono móvil era utilizado por $100 \%$ de los estudiantes y el 100\% lo utiliza a diario.

En el figura 1 aparece la distribución de las horas que los estudiantes dedican a internet y al teléfono móvil cada día. En referencia del uso de internet, la media global es de 2,03 donde la puntuación "2" hace referencia a un uso "entre 3 y 5 horas" y la puntuación " 3 " a "más de 5 horas". Atendiendo al criterio establecido de segregación por cursos, los estudiantes de primero obtuvieron una media de 2,2 con una distribución de frecuencias de manera decreciente, el $46,4 \%$ le dedica "más de 5 horas", el $25 \%$ " de " 3 a 5 horas" y el 26,8\% "entre 1 y 3 horas". Los estudiantes de cuarto curso obtuvieron una media de 1,82 donde la puntuación "1" hace referencia a un uso "entre 1 y 3 horas" y la puntuación "2" a "entre 3 y 5 horas". En la distribución de frecuencias, el $26,9 \%$ eligió la opción "más de 5 horas", el 30,8\% de "3 a 5 horas" y el 42,3\% de "1 a 3 horas".

En el uso del teléfono móvil, la muestra obtuvo una puntuación media de 2,44 donde la puntuación "2" hace referencia a un uso "entre 3 y 5 horas" y la puntuación " 3 " a "más de 5 horas". Los estudiantes de primer curso obtuvieron una media de 2,55 donde el $62,5 \%$ le dedicaba "más de 5 horas", el $26,8 \%$ de " 3 a 5 horas" y el $8,9 \%$ de "1 a 3 horas". Entre los estudiantes de cuarto curso, con una puntuación media de 2,33, el 53,8\% dedicaba "más de 5 horas", el $25 \%$ de " 3 a 5 horas" y el 14,8\% de "1 a 3 horas". En el figura 2 se indica la distribución de los estudiantes en función del uso semanal que hacen de las NT. Atendiendo al uso de Internet se obtuvo una media global de 3,5, donde la puntuación " 3 " hace referencia a un uso "entre 5 y 10 horas" y la puntuación "4" a "más de 10 horas". Los alumnos de primer curso obtuvieron una media de 3,66. De modo descendiente, el $75 \%$ de los estudiantes declararon utilizar internet "más de 10 horas" a la semana, el 16,1\% "entre 5 y 10 horas" y el 8,9\% "entre 2 y 5 horas". Los alumnos de cuarto curso obtuvieron una media de 3,33. El 53,8\% de los estudiantes utilizaba internet "más de 10 horas", el 26,9\% "entre 5 y 10 horas" el 17,3\% "entre 2 y 5 horas" y el $0,9 \%$ "entre 1 y 2 horas". En el uso del teléfono móvil, los estudiantes obtienen una media global de 3,76. Segregados por cursos, los estudiantes de primer curso obtuvieron una puntuación media de 3,76 . De ellos, el $82,1 \%$ usaba "más de 10 horas", el $8,9 \%$ "entre 5 y 10 horas" y el $7,1 \%$ "entre 2 y 5 horas". Los estudiantes de cuarto curso obtuvieron una puntuación media de 3,75. El 76,9\% de ellos le dedicaron "más de 10 horas", el $21,2 \%$ "entre 5 y 10 horas" y el 1,9\% "entre 2 y 5 horas". 


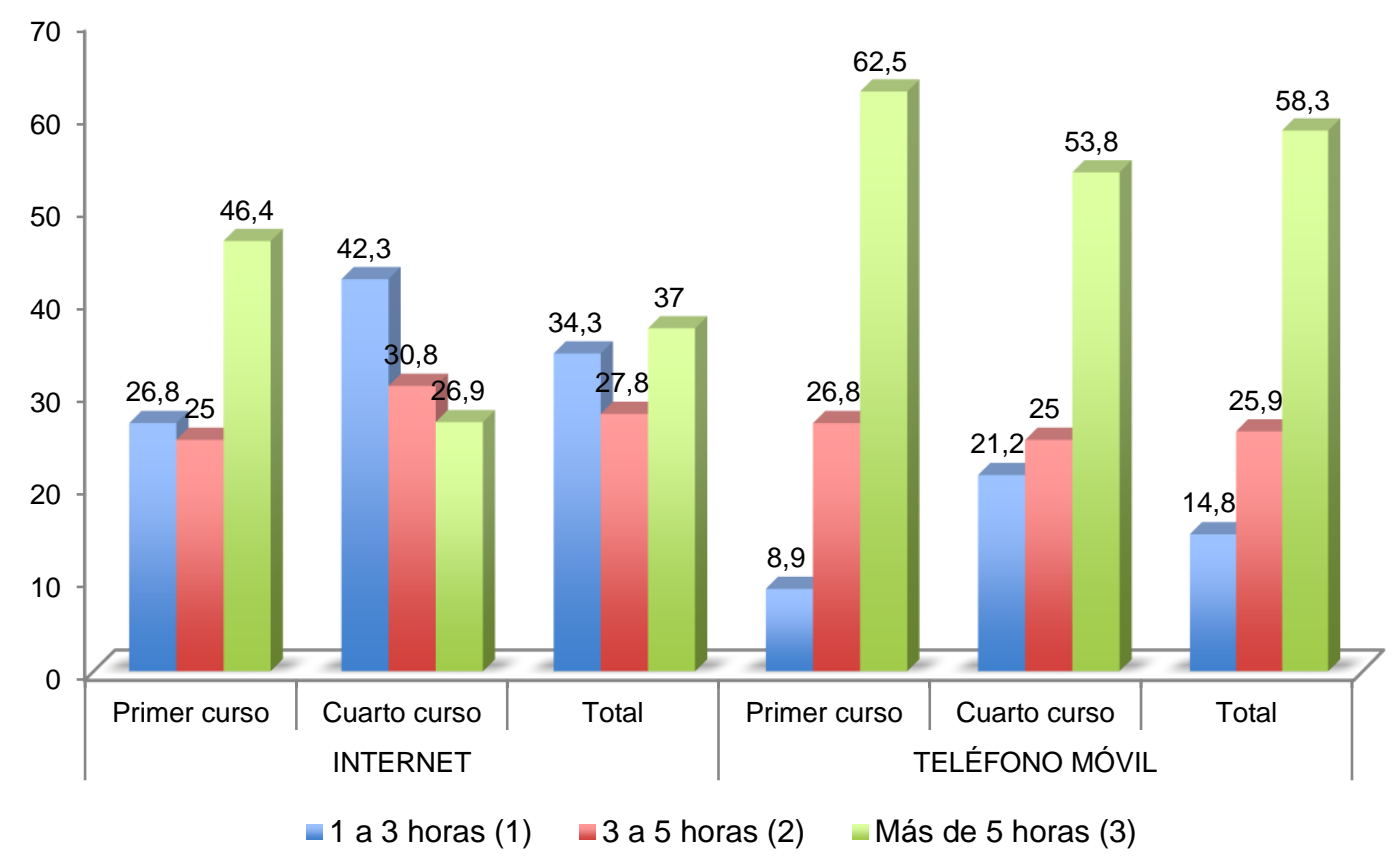

Fig. 1. Frecuencias sobre las horas dedicadas al día

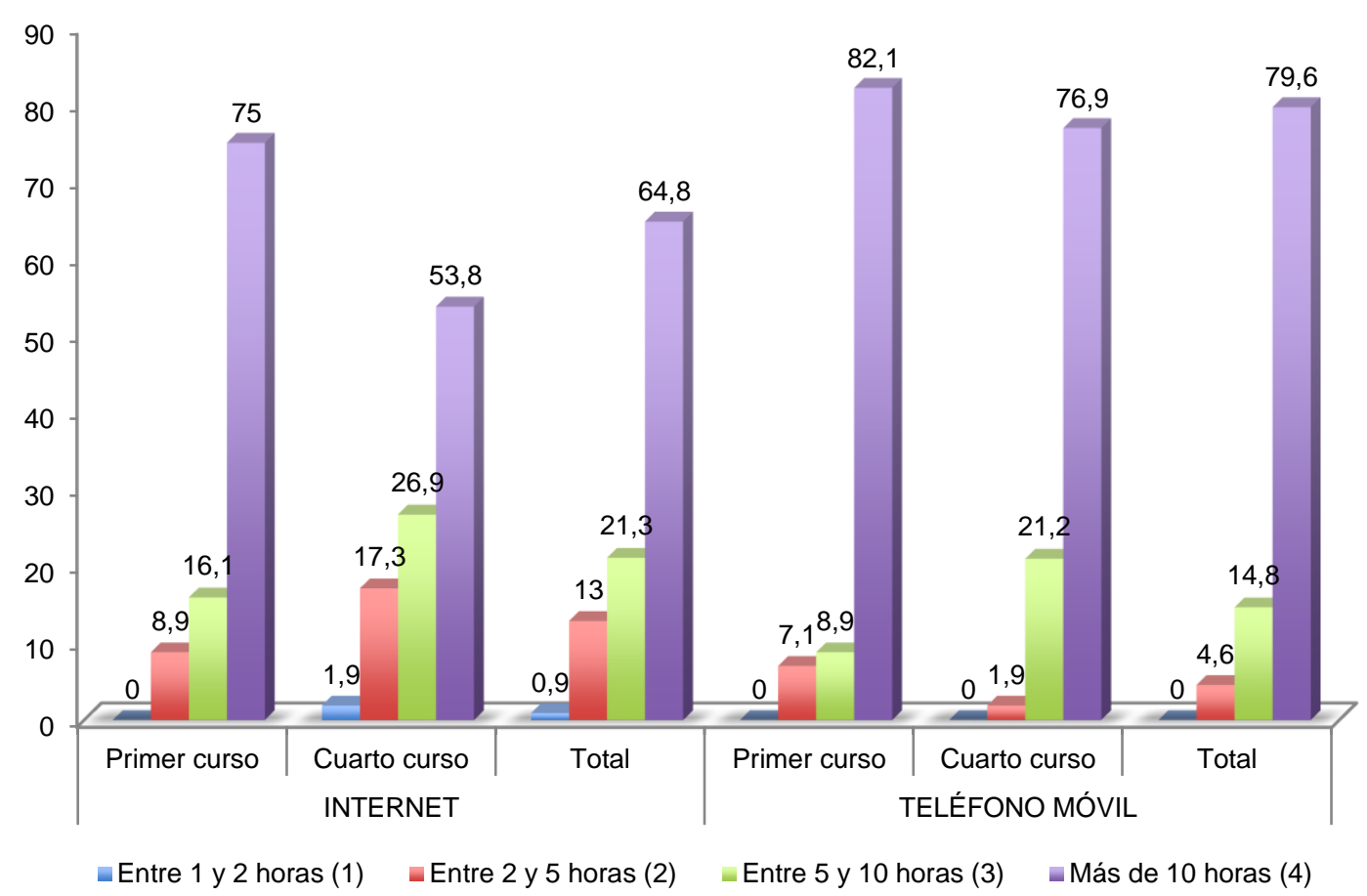

Fig. 2. Frecuencias sobre las horas dedicadas a la semana

A continuación analizamos cada uno de los ítems que describen cómo fue el uso de las NT para conocer las respuestas de la muestra en cada subescala, analizando cuál tienen mayor o menor repercusión. En relación al uso de internet, en la tabla 1 aparece la descripción de los siete ítems que lo forman. El ítem 6: "¿Dedicas más tiempo del que crees necesario a internet?" se obtuvo una media global de 2,56 donde la puntuación "2" hace referencia a "a veces" y la puntuación "3" a "con frecuencia". De los alumnos de primer curso, el 92,9\% respondió afirmativamente, de ellos, el 39,3\% respondió "a veces", el 32,1\% "con frecuencia" y el 21,4\% "siempre". De los estudiantes de cuarto curso, el 88,5\% respondió afirmativamente, de ellos, el 46,2\% respondió "a veces", el 28,8\% "con frecuencia" y el 13,5\% "siempre". 
Tabla 1. Estadísticos descriptivos y frecuencias de uso de Internet en los ítems 6-12

\begin{tabular}{|c|c|c|c|c|c|c|c|c|c|c|c|c|c|}
\hline \multirow{2}{*}{ Ítem } & \multirow{2}{*}{ Curso } & \multicolumn{2}{|c|}{ Nunca (1) } & \multicolumn{2}{|c|}{$A$ veces (2) } & \multicolumn{2}{|c|}{ Con frecuencia (3) } & \multicolumn{2}{|c|}{ Siempre (4) } & \multicolumn{4}{|c|}{ Total } \\
\hline & & $N$ & $\%$ & $N$ & $\%$ & $N$ & $\%$ & $N$ & $\%$ & $\%$ & $N$ & Media & $\sigma$ \\
\hline \multirow{3}{*}{6} & $1^{0}$ & 4 & 7,1 & 22 & 39,3 & 18 & 32,1 & 12 & 21,4 & 100 & 56 & 2,68 & ,897 \\
\hline & $4^{\circ}$ & 6 & 11,5 & 24 & 46,2 & 15 & 28,8 & 7 & 13,5 & 100 & 52 & 2,44 & ,873 \\
\hline & Total & 10 & 9,3 & 46 & 42,6 & 33 & 30,6 & 19 & 17,6 & 100 & 108 & 2,56 & ,889 \\
\hline \multirow{3}{*}{7} & $1^{0}$ & 16 & 28,6 & 29 & 51,8 & 7 & 12,5 & 4 & 7,1 & 100 & 56 & 1,98 & ,842 \\
\hline & $4^{\circ}$ & 17 & 32,7 & 21 & 40,4 & 7 & 13,5 & 7 & 13,5 & 100 & 52 & 2,08 & 1,007 \\
\hline & Total & 33 & 30,6 & 50 & 46,3 & 14 & 13,0 & 11 & 10,2 & 100 & 108 & 2,03 & ,922 \\
\hline \multirow{3}{*}{8} & $1^{\circ}$ & 34 & 60,7 & 15 & 26,8 & 4 & 7,1 & 3 & 5,4 & 100 & 56 & 1,57 & ,850 \\
\hline & $4^{\circ}$ & 33 & 63,5 & 18 & 34,6 & 1 & 1,9 & 0 & 0 & 100 & 52 & 1,38 &, 530 \\
\hline & Total & 67 & 62,0 & 33 & 30,6 & 5 & 4,6 & 3 & 2,8 & 100 & 108 & 1,48 & ,717 \\
\hline \multirow{3}{*}{9} & $1^{0}$ & 48 & 85,7 & 7 & 12,5 & 1 & 1,8 & 0 & 0 & 100 & 56 & 1,16 & ,417 \\
\hline & $4^{0}$ & 47 & 90,4 & 4 & 7,7 & 1 & 1,9 & 0 & 0 & 100 & 52 & 1,12 & ,379 \\
\hline & Total & 95 & 88,0 & 11 & 10,2 & 2 & 1,9 & 0 & 0 & 100 & 108 & 1,14 & 398 \\
\hline \multirow{3}{*}{10} & $1^{0}$ & 38 & 67,9 & 13 & 23,2 & 4 & 7,1 & 1 & 1,8 & 100 & 56 & 1,43 & ,710 \\
\hline & $4^{\circ}$ & 35 & 67,3 & 13 & 25,0 & 4 & 7,7 & 0 & 0 & 100 & 52 & 1,40 & ,634 \\
\hline & Total & 73 & 67,6 & 26 & 24,1 & 8 & 7,4 & 1 & 0,9 & 100 & 108 & 1,42 & ,672 \\
\hline \multirow{3}{*}{11} & $1^{0}$ & 9 & 16,1 & 27 & 48,2 & 16 & 28,6 & 4 & 7,1 & 100 & 56 & 2,27 & ,820 \\
\hline & $4^{\circ}$ & 11 & 21,2 & 24 & 46,2 & 15 & 28,8 & 2 & 3,8 & 100 & 52 & 2,15 & ,802 \\
\hline & Total & 20 & 18,5 & 51 & 47,2 & 31 & 28,7 & 6 & 5,6 & 100 & 108 & 2,21 & ,809 \\
\hline \multirow{3}{*}{12} & $1^{\circ}$ & 38 & 67,9 & 14 & 25,0 & 0 & 0 & 4 & 7,1 & 100 & 56 & 1,46 & ,830 \\
\hline & $4^{\circ}$ & 30 & 57,7 & 19 & 36,5 & 1 & 1,9 & 2 & 3,8 & 100 & 52 & 1,52 & ,727 \\
\hline & Total & 68 & 63,0 & 33 & 30,6 & 1 & 0,9 & 6 & 5,6 & 100 & 108 & 1,49 & ,779 \\
\hline
\end{tabular}

El ítem 7: “¿Te encuentras mal cuando por algún motivo no puedes utilizar internet queriendo hacerlo?” se obtuvo una media global de 2,03 donde la puntuación "2" hace referencia a "a veces" y la puntuación "3" a "con frecuencia". Del $71,4 \%$ de los alumnos de primer curso que respondieron afirmativamente, el $51,8 \%$ respondió "a veces", el 12,5\% "con frecuencia" y el 7,1\% "siempre". De los alumnos de cuarto curso, el 67,3\% respondió afirmativamente, de ellos el 40,4\% respondió "a veces", el 13,5\% "con frecuencia" y el 13,5\% "siempre". En el ítem 8:" ¿Estás pensando desde horas antes de conectarte a internet en ello?" con una media global de 1,48 donde la puntuación "1" hace referencia a "nunca" y la puntuación "2" a "a veces". De los alumnos de primer curso, el 39,3\% respondió afirmativamente, de ellos el $26,8 \%$ indico "a veces", el $7,1 \%$ "con frecuencia" y el 5,4\% "siempre". De los alumnos de cuarto curso, el 38\% respondió afirmativamente en diferentes grados, el 34,6\% indicó "a veces" y el 1,9\% "con frecuencia".

En el ítem 9: “¿Mientes a tu familia o amigos sobre las horas que dedicas a utilizar internet?” la media global fue de 1,14 donde la puntuación "1" hace referencia a "nunca" y la puntuación "2" a "a veces". El 85,7\% de los alumnos de primer curso indicaron la opción "nunca", el 12,5\% "a veces" y el 1,8\% "con frecuencia". De los alumnos de cuarto curso, el 90,4\% indicó "nunca", el 7,7\% "a veces" y el 1,9\% "con frecuencia". Para el ítem 10: “¿Alguna vez has intentado desconectarte de internet y no lo has conseguido?” se obtuvo una media global de 1,42 donde la puntuación "1" hace referencia a "nunca" y la puntuación "2" a "a veces". De los alumnos de primer curso que respondieron afirmativamente $(32,1 \%)$, el $23,2 \%$ indicó "a veces", el $7,1 \%$ "con frecuencia" y el 1,8\% "siempre". Los alumnos de cuarto curso indicaron el $67,3 \%$ "nunca", el $25 \%$ "a veces" y el $7,7 \%$ "con frecuencia".

En el ítem 11: “¿Te relaja navegar por internet?" se obtuvo una media global de 2,21 donde la puntuación "2" hace referencia a "a veces" y la puntuación "3" a "con frecuencia". La respuesta de los alumnos de primer curso fue 16,1\% "nunca", 48,2\% "a veces", $28,6 \%$ "con frecuencia" y 7,1\% "siempre". Los alumnos de cuarto curso, 21,2\% "nunca", 46,2\% "a veces", 28,8\% "con frecuencia" y 3,8\% "siempre". Por último, en el ítem 12: “¿Te sientes nervioso si pasa mucho tiempo desde la última vez que estuviste conectado a internet?" se obtuvo una media global de 1,49 donde la puntuación "1" hace referencia a "nunca" y la puntuación "2" a "a veces". Entre los alumnos de primer curso, el 67,9\% respondió "nunca", el 25\% "a veces" y el 7,1\% "siempre". De los alumnos de cuarto curso, el $57,7 \%$ respondió "nunca", el 36,5\% "a veces", el 1,9\% "con frecuencia" y el 3,8\% "siempre". 
En la tabla 2, aparece la descripción de los seis ítems referidos al uso del teléfono móvil. El ítem 27: "Te encuentras mal cuando por algún motivo no puedes usar el teléfono móvil?" La puntuación media global fue de 2.17 donde la puntuación "2" hace referencia a "a veces" y la puntuación "3" a "con frecuencia". Entre los estudiantes de primer curso, el $78.6 \%$ respondió afirmativamente aunque en diferente grado, el $55,4 \%$ respondió que "a veces", el $17.9 \%$ "con frecuencia" y el 5.4 "siempre". De los estudiantes de cuarto curso, el $84.6 \%$ respondió que sí, en diferente medida, el $53.8 \%$ indicó que "a veces", el $19.2 \%$ "con frecuencia" y el $11.5 \%$ "siempre".

En el ítem 28: “¿Estás pensando desde horas antes de usar el móvil?" con una media global de 1,75 donde la puntuación "1" es "nunca" y la puntuación "2" es "a veces". Entre los estudiantes de primer curso, el 46,4\% respondió negativamente, el $37,5 \%$ respondió que "a veces", el 12,5\% "con frecuencia" y el 3,6\% "siempre". Los estudiantes de cuarto curso respondieron negativamente el $40,4 \%$, el $44,2 \%$ "a veces", el $13,5 \%$ "con frecuencia" y el 1,9 "siempre". En el ítem 29: "¿Mientes a tu familia o amigos sobre las horas que dedicas al móvil?" se obtuvo una media global de 1,23 donde la puntuación "1" hace referencia a "nunca" y la puntuación "2" a "a veces". De los alumnos de primer curso el $80,4 \%$ respondió negativamente, el 14,3\% "a veces", el $3,6 \%$ "con frecuencia" y el 1,8\% "siempre". Entre los alumnos de cuarto curso el $86,5 \%$ respondió "nunca", el 9,6 "a veces", el 1,9\% "con frecuencia" y el 1,9\% "siempre".

Para el ítem 30: “¿Alguna vez has intentado dejar el móvil y no lo has conseguido?" se obtuvo una media global de 1,81 donde la puntuación "1" hace referencia a "nunca" y la puntuación "2" a "a veces". Entre los estudiantes de primer curso, el 58,9\% respondió afirmativamente, de ellos, el 39,3\% respondió "a veces", el 16,1\% "con frecuencia" y el 3,6\% "siempre". En el ítem 31: "¿Te relaja usar el móvil?" se obtuvo una media global de 2,33 donde la puntuación "2" hace referencia a "a veces" y la puntuación "3" a "con frecuencia". Los alumnos de primer curso, con una media de 2,48 el $8,9 \%$ respondieron negativamente, el $50 \%$ "a veces", el $25 \%$ "con frecuencia" y el 16,1\% "siempre". De los alumnos de cuarto curso, con una media de 2,17 , el 15,4\% respondió "nunca", el 59,6\% "a veces", el 17,3\% "con frecuencia" y el 7,7\% "siempre".

Por último, en el ítem 32: “ ¿Te sientes nervioso si pasa mucho tiempo desde la última vez que usaste el móvil?" se obtuvo una media global de 1,84 donde la puntuación "1" hace referencia a "nunca" y la puntuación "2" a "a veces". De los estudiantes de primer curso, con una media de 1,68, el 55,4\% respondió "nunca", el $26,8 \%$ "a veces", el 12,5\% "con frecuencia" y el 5,4\% "siempre". Entre los estudiantes de cuarto curso obtuvieron una media de 2,02 con la siguiente distribución, el 32,7\% respondió negativamente, el 40,4\% respondió "a veces", el 15,4\% "con frecuencia" y el 9,6\% "siempre".

Tabla 2. Estadísticos descriptivos y frecuencias de uso del teléfono móvil en los ítems 27-32

\begin{tabular}{|c|c|c|c|c|c|c|c|c|c|c|c|c|c|}
\hline \multirow{2}{*}{ Ítem } & \multirow{2}{*}{ Curso } & \multicolumn{2}{|c|}{ Nunca (1) } & \multicolumn{2}{|c|}{$A$ veces (2) } & \multicolumn{2}{|c|}{ Con frecuencia (3) } & \multicolumn{2}{|c|}{ Siempre 4) } & \multicolumn{4}{|c|}{ Total } \\
\hline & & $N$ & $\%$ & $N$ & $\%$ & $N$ & $\%$ & $N$ & $\%$ & $\%$ & $N$ & Media & $\sigma$ \\
\hline \multirow{3}{*}{27} & $1^{0}$ & 12 & 21,4 & 31 & 55,4 & 10 & 17,9 & 3 & 5,4 & 100 & 56 & 2,07 & ,783 \\
\hline & $4^{\circ}$ & 8 & 15,4 & 28 & 53,8 & 10 & 19,2 & 6 & 11,5 & 100 & 52 & 2,27 & 8,866 \\
\hline & Total & 20 & 18,5 & 59 & 54,6 & 20 & 18,5 & 9 & 8,3 & 100 & 108 & 2,17 & ,826 \\
\hline \multirow{3}{*}{28} & $1 \stackrel{0}{ }$ & 26 & 46,4 & 21 & 37,5 & 7 & 12,5 & 2 & 3,6 & 100 & 56 & 1,73 & ,820 \\
\hline & $4^{\circ}$ & 21 & 40,4 & 23 & 44,2 & 7 & 13,5 & 1 & 1,9 & 100 & 52 & 1,77 & ,757 \\
\hline & Total & 47 & 43,5 & 44 & 40,7 & 14 & 13,0 & 3 & 2,8 & 100 & 108 & 1,75 & ,787 \\
\hline \multirow{3}{*}{29} & $1^{0}$ & 45 & 80,4 & 8 & 14,3 & 2 & 3,6 & 1 & 1,8 & 100 & 56 & 1,27 & ,618 \\
\hline & $4^{\circ}$ & 45 & 86,5 & 5 & 9,6 & 1 & 1,9 & 1 & 1,9 & 100 & 52 & 1,19 & ,561 \\
\hline & Total & 90 & 83,3 & 13 & 12,0 & 3 & 2,8 & 2 & 1,9 & 100 & 108 & 1,23 &, 590 \\
\hline \multirow{3}{*}{30} & 10 & 23 & 41,1 & 22 & 39,3 & 9 & 16,1 & 2 & 3,6 & 100 & 56 & 1,82 & 834 \\
\hline & $4^{\circ}$ & 21 & 40,4 & 21 & 40,4 & 9 & 17,3 & 1 & 1,9 & 100 & 52 & 1,81 & 793 \\
\hline & Total & 44 & 40,7 & 43 & 39,8 & 18 & 16,7 & 3 & 2,8 & 100 & 108 & 1,81 & 811 \\
\hline \multirow{3}{*}{31} & 10 & 5 & 8,9 & 28 & 50,0 & 14 & 25,0 & 9 & 16,1 & 100 & 56 & 2,48 & 874 \\
\hline & $4^{\circ}$ & 8 & 15,4 & 31 & 59,6 & 9 & 17,3 & 4 & 7,7 & 100 & 52 & 2,17 & ,785 \\
\hline & Total & 13 & 12,0 & 59 & 54,6 & 23 & 21,3 & 13 & 12,0 & 100 & 108 & 2,33 & ,843 \\
\hline \multirow{3}{*}{32} & $1^{\circ}$ & 31 & 55,4 & 15 & 26,8 & 7 & 12,5 & 3 & 5,4 & 100 & 56 & 1,68 & ,897 \\
\hline & $4^{\circ}$ & 17 & 32,7 & 21 & 40,4 & 8 & 15,4 & 5 & 9,6 & 98,1 & 51 & 2,02 & 948 \\
\hline & Total & 48 & 44,4 & 36 & 33,3 & 15 & 13,9 & 8 & 7,4 & 99,1 & 107 & 1,84 & 933 \\
\hline
\end{tabular}


En la tabla 3 se indica la frecuencia, la media y la desviación típica de la aparición de problemas, en los estudiantes, debido al uso excesivo de internet y del teléfono móvil. En el uso de Internet, la puntuación media obtenido en los alumnos de primero fue de 1,83 y en los alumnos de cuarto de 1,81 (donde la puntuación 1 significa "nunca" y la puntuación 2 "a veces"). Se encontró que entre los alumnos de primer curso, el 44,6\% nunca ha tenido problemas consecuencia del uso excesivo de internet y el teléfono móvil; en el $26,8 \%$, el uso de estas tecnologías, a veces le ha causado problemas; en el $21,4 \%$ con frecuencia ha sido causa de problemas; y el 3,6\% de los alumnos siempre ha sido motivo de problemas. Entre los alumnos de cuarto curso el $51,9 \%$ nunca ha tenido problemas derivados de su uso; el $23,1 \%$ ha tenido problemas a veces; al $17,3 \%$ de los alumnos con frecuencia le ha causado problemas; y al 7,7\% el uso de estas tecnologías siempre ha sido motivo de problemas.

Tabla 3. Estadísticos descriptivos y frecuencias con que causan problemas por dedicar exceso de tiempo a internet y el teléfono móvil

\begin{tabular}{|c|c|c|c|c|c|c|c|c|c|c|c|c|c|}
\hline \multirow{2}{*}{$N T$} & \multirow{2}{*}{ Curso } & \multicolumn{2}{|c|}{ Nunca(1) } & \multicolumn{2}{|c|}{$A$ veces(2) } & \multicolumn{2}{|c|}{ Con frecuencia(3) } & \multicolumn{2}{|c|}{ Siempre(4) } & \multicolumn{4}{|c|}{ Total } \\
\hline & & $N$ & $\%$ & $N$ & $\%$ & $N$ & $\%$ & $N$ & $\%$ & $\%$ & $N$ & Media & $\sigma$ \\
\hline \multirow{3}{*}{ 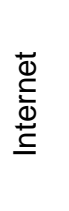 } & $1^{0}$ & 25 & 44,6 & 15 & 26,8 & 12 & 21,4 & 2 & 3,6 & 96,4 & 54 & 1,83 & ,906 \\
\hline & $4^{\circ}$ & 27 & 51,9 & 12 & 23,1 & 9 & 17,3 & 4 & 7,7 & 100 & 52 & 1,81 & 991 \\
\hline & Total & 52 & 48,1 & 27 & 25,0 & 21 & 19,4 & 6 & 5,6 & 98,1 & 106 & 1,82 & ,944 \\
\hline \multirow{3}{*}{ 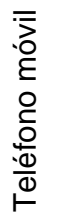 } & $1^{\circ}$ & 12 & 21,4 & 20 & 35,7 & 16 & 28,6 & 6 & 10,7 & 96,4 & 54 & 2,3 & 944 \\
\hline & $4^{\circ}$ & 10 & 19,2 & 22 & 42,3 & 15 & 28,8 & 5 & 9,6 & 100 & 52 & 2,29 & ,893 \\
\hline & Total & 22 & 20,4 & 42 & 38,9 & 31 & 28,7 & 11 & 10,2 & 98,1 & 106 & 2,29 & ,915 \\
\hline
\end{tabular}

Con respecto al uso del teléfono móvil, la puntuación media para los estudiantes de primero fue de 2,30 y para los estudiantes de cuarto curso de 2,29 (donde la puntuación 2 significa"a veces" y la puntuación 3 "con frecuencia"). Ente los estudiantes de primer curso, el 21,4\% no tuvieron ningún problema secundario al tiempo empleado en el uso del teléfono móvil, al 35,7\% le ha causado problemas a veces, al $28,6 \%$ con frecuencia y al $10,7 \%$ siempre. En los estudiantes de cuarto, al 19,2\% no les ha causado nunca problemas su uso, al $42,3 \%$ les ha generado problemas a veces, al $28,8 \%$ les causa problemas con frecuencia y al $9,6 \%$ les causa problemas siempre.

En la tabla 4 se muestra la comparación de medias entre los alumnos de primer y cuarto curso en relación al uso que hacen de internet. Se encontró una diferencia estadísticamente significativa entre las valoraciones obtenidas para los alumnos de primer y cuarto curso en el ítem 5 "¿Cuántas horas dedicas a internet al día?" $(3.66 \pm 0.64 ; 3.33 \pm 0.83 ; p=0.021)$ y en el ítem 6 : ¿Dedicas más tiempo del que crees necesario a internet?" $(2.20 \pm 0.85 ; 1.85 \pm 0.83 ; p=0.031)$.

Tabla 4. Análisis del uso de internet entre alumnos de primer y cuarto curso

\begin{tabular}{|c|c|c|c|c|c|c|c|}
\hline \multirow{2}{*}{$\begin{array}{l}\text { Internet } \\
\text { Ítem }\end{array}$} & \multirow{2}{*}{$\begin{array}{l}\text { Primer Curso } \\
\quad(n=56)\end{array}$} & \multirow{2}{*}{$\begin{array}{l}\text { Cuarto Curso } \\
\quad(n=52)\end{array}$} & \multirow[b]{2}{*}{ Valor de $p$} & \multicolumn{2}{|c|}{ Intervalo Confianza } & \multirow[b]{2}{*}{ gl } & \multirow[b]{2}{*}{$t$} \\
\hline & & & & $\begin{array}{l}\text { Límite } \\
\text { Inferior }\end{array}$ & $\begin{array}{l}\text { Límite } \\
\text { Superior }\end{array}$ & & \\
\hline 1.1 & $3.98 \pm 0.13$ & $4.00 \pm 0.00$ & .338 & 3.97 & 4.01 & 1 & -0.96 \\
\hline 2.1 & $1.83 \pm 0.91$ & $1.81 \pm 0.99$ & .890 & 1.64 & 2.00 & 1 & 0.14 \\
\hline 4 & $1.75 \pm 1.46$ & $1.77 \pm 1.54$ & .947 & 1.47 & 2.04 & 1 & 2.34 \\
\hline 5 & $3.66 \pm 0.64$ & $3.33 \pm 0.83$ & .021 & 3.36 & 3.64 & 1 & 2.18 \\
\hline 6 & $2.20 \pm 0.85$ & $1.85 \pm 0.83$ & .031 & 1.86 & 2.19 & 1 & 1.39 \\
\hline 7 & $2.68 \pm 0.90$ & $2.44 \pm 0.87$ & .169 & 2.40 & 2.73 & 1 & -0.53 \\
\hline 8 & $1.98 \pm 0.84$ & $2.08 \pm 1.01$ & .596 & 1.85 & 2.20 & 1 & 1.36 \\
\hline 9 & $1.57 \pm 0.85$ & $1.38 \pm 0.53$ & .177 & 1.34 & 1.62 & 1 & 0.59 \\
\hline 10 & $1.16 \pm 0.42$ & $1.12 \pm 0.38$ & .556 & 1.06 & 1.21 & 1 & 0.19 \\
\hline 11 & $1.43 \pm 0.71$ & $1.40 \pm 0.63$ & .849 & 1.29 & 1.54 & 1 & 0.73 \\
\hline 12 & $2.27 \pm 0.82$ & $2.15 \pm 0.80$ & .467 & 2.06 & 2.37 & 1 & -0.37 \\
\hline
\end{tabular}


En la tabla 5 mostramos los resultados de la comparación de medias entre los alumnos de primer y cuarto curso en relación al uso que hacen del teléfono móvil, sin embargo no se encontraron diferencias estadísticas significativas entre las valoraciones obtenidas para los alumnos de primer y cuarto curso.

Tabla 5. Análisis del uso del teléfono móvil entre alumnos de primer y cuarto curso

\begin{tabular}{|c|c|c|c|c|c|c|c|}
\hline \multirow[b]{2}{*}{$\begin{array}{l}\text { Teléfono } \\
\text { Móvil Ítem }\end{array}$} & \multirow[b]{2}{*}{$\begin{array}{l}\text { Primer Curso } \\
\quad(n=56)\end{array}$} & \multirow[b]{2}{*}{$\begin{array}{l}\text { Cuarto Curso } \\
\quad(n=52)\end{array}$} & \multirow[b]{2}{*}{ Valor de $p$} & \multicolumn{2}{|c|}{ Intervalo Confianza } & \multirow[b]{2}{*}{ gl } & \multirow[b]{2}{*}{$t$} \\
\hline & & & & $\begin{array}{l}\text { Límite } \\
\text { Inferior }\end{array}$ & $\begin{array}{l}\text { Límite } \\
\text { Superior }\end{array}$ & & \\
\hline 1.4 & $4.00 \pm 0.00$ & $4.00 \pm 0.00$ & - & 4.00 & 4.00 & 1 & - \\
\hline 2.4 & $2.30 \pm 0.94$ & $2.29 \pm 0.89$ & .965 & 2.12 & 2.47 & 1 & 0.04 \\
\hline 25 & $3.76 \pm 0.58$ & $3.75 \pm 0.48$ & .215 & 3.66 & 3.86 & 1 & 0.13 \\
\hline 26 & $2.55 \pm 0.66$ & $2.33 \pm 0.81$ & .808 & 2.30 & 2.58 & 1 & 1.53 \\
\hline 27 & $2.07 \pm 0.78$ & $2.27 \pm 0.87$ & .508 & 2.01 & 2.32 & 1 & -1.25 \\
\hline 28 & $1.73 \pm 0.82$ & $1.77 \pm 0.76$ & .930 & 1.60 & 1.90 & 1 & -0.24 \\
\hline 29 & $1.27 \pm 0.62$ & $1.19 \pm 0.56$ & .056 & 1.12 & 1.34 & 1 & 0.66 \\
\hline 30 & $1.82 \pm 0.83$ & $1.81 \pm 0.79$ & .059 & 1.66 & 1.97 & 1 & 0.09 \\
\hline 31 & $2.48 \pm 0.87$ & $2.17 \pm 0.79$ & .895 & 2.17 & 2.49 & 1 & 1.93 \\
\hline 32 & $1.68 \pm 0.90$ & $2.02 \pm 0.95$ & .128 & 1.66 & 2.02 & 1 & -1.91 \\
\hline
\end{tabular}

Una vez llevada a cabo la exposición de los resultados de la investigación podemos afirmar que los estudiantes universitarios dedican gran cantidad de tiempo al teléfono móvil y a internet. En concreto, más de la mitad $(58,3 \%)$ de la muestra dedicó diariamente al teléfono móvil más de cinco horas y semanalmente el $76,9 \%$ dedicó más de 10 horas. Esta dedicación ha generado, a más de dos tercios de ellos (79,6\%), en algún momento algún problema secundario al excesivo tiempo dedicado. Además, el 38,9\% de los mismos tenía problemas siempre o con frecuencia por su uso.

El relación al tiempo destinado diariamente a internet, el $37 \%$ de la muestra dedica más de cinco horas diarias y el $64,8 \%$ dedica más de diez horas semanales a estar conectado. Llegando a las 35 horas dedicadas a la semana, coincidiendo con Yang y Tung (2007), en que una media semanal de mayor de 28 horas aumenta las probabilidades de desarrollar problemas derivados del exceso de uso. En algún momento, este uso excesivo ha generado problema a más de la mitad de los estudiantes $(51,9 \%)$. De ellos, el $25 \%$ ha tenido problemas con frecuencia o siempre. En la última década, el uso del teléfono móvil y de internet ha crecido exponencialmente. En el 2008 el 2,2\% de la población universitaria se conecta varias veces al día y el 76,2\% lo hace varias veces a la semana (García et. al., 2008). Actualmente, el $100 \%$ de los estudiantes se conecta a diario. Gracias al uso de internet en el teléfono móvil, la actitud hacia su uso y manejo de aplicaciones de los jóvenes y de los universitarios es buena, existe un optimismo tecnológico (Ruiz y Belmonte, 2014). El teléfono móvil (smartphone) se ha convertido en el principal dispositivo de conexión a internet por los españoles frente al ordenador (Fundación Telefónica, 2016).

Ya Ruiz-Palmero, Sánchez-Rodríguez y Trujillo-Torres (2016) indicaban, en etapas anteriores a la universitaria, que un 39,5\% de jóvenes adolescentes mostraban problemas importantes por el uso abusivo del teléfono móvil. Entre los distintos problemas, Giménez, Maquilón y Arnáiz (2015) observan que el cyberbulling aparece en el $8 \%$ de los estudiantes de primaria, secundaria y bachillerato como conducta problemática generada por el uso de las TIC. Estos alumnos muestran conductas de agresividad, ansiedad y cambios de interés asociados al uso de las TIC. Para dar respuesta a esta situación, hay que considerar esta relación existente entre la sintomatología depresiva y ansiosa y el uso problemático de internet y del teléfono móvil. Este uso indebido puede afectar también a la autoestima, donde un mayor uso de las nuevas tecnología se relaciona con niveles bajos de la misma (González y Estévez, 2017). Fernández-Villa et al. (2015) indican que el $6 \%$ de los universitarios muestran problemas frecuentes con el uso de internet, con repercusiones en su vida social. Otros autores (Alavi et al., 2012; Kaess et al., 2014) describen síntomas depresivos asociados a una adicción a internet.

Se encontraron diferencias estadísticamente significativas $(p<0.05)$ entre los alumnos de primer y cuarto curso con respecto al uso de internet diaria y semanalmente. Los alumnos de primer curso dedicaron más tiempo a internet que los alumnos de cuarto. Este resultado coincide con Ruiz (2016), quien también encuentra un uso más frecuente de estas tecnologías entre los sujetos más jóvenes. Sin embargo, no se hallaron diferencias significativas entre alumnos de primero y cuarto con respecto al uso del teléfono móvil.

Alguna de las limitaciones que presenta la investigación son, la utilización de un único autoinforme para conocer el uso de los estudiantes en el manejo de las TIC, probablemente, la formación de un grupo de 
discusión contribuiría en completar la información. El reducido número de varones en el estudio no hace viable la posibilidad de diferenciar los resultados en función del género, sería conveniente disponer en futuros estudios de un mayor reparto intencional en la variable género.

Por tanto, actualmente necesitamos afrontar el reto de reconducir cómo utilizar y cómo servirnos de estas herramientas para que no interfieran en nuestro desarrollo personal, social y educativo, como hemos podido analizar en la investigación, y lograr su buen uso. Las TIC tienen un gran potencial para el desarrollo personal y educativo y, por lo tanto, es necesario enseñar a los estudiantes a administrar adecuadamente las herramientas que están a su alcance. Sin olvidar las actividades interactivas con los compañeros y el profesorado, porque estos alumnos tienen más éxito académico que aquellos se sólo las utilizan para buscar información (Torres, Duart, Gómez, Marín y Segarra, 2016).

\section{CONCLUSIONES}

Considerando los resultados obtenidos, su discusión y análisis, se realizan cuatro conclusiones; primero, los estudiantes dedican una gran cantidad de su tiempo al uso de las nuevas tecnologías, llegando a ser excesiva en muchos de ellos. Segundo, sus características de uso muestran la necesidad que tienen de estar conectados, anticipándose en algunos casos a la posibilidad de que no puedan conectarse, y de convertirse en una herramienta que les relaje, probablemente por la actitud pasiva que requiere. Tercero, debemos considerar el impacto de los problemas asociados al mal uso de las TIC, como malestar por ser incapaz de desconectarse, mentir al circulo más cercano sobre el tiempo que dedican y dependencia, con la necesidad de consultar frecuentemente el móvil. Por último, estos datos nos llevan a afirmar que la población universitaria ha integrado el uso de las TIC, pero que es necesario saber dosificarlo para que en vez de convertirse en una herramienta, se convierta en una dependencia.

\section{REFERENCIAS}

Alavi, S., Ferdosi, M., Jannatifard, F., Eslami, M., Alaghemandan, H. y Setare, M., Behavioral Addiction versus Substance Addiction: Correspondence of Psychiatric and Psychological Views. International Journal of Preventive Medicine, 3, 290294 (2012)

American Psychiatric Association, Guía de consulta de los criterios diagnósticos del DSM-V. Editorial médica panamericana, Madrid, España (2013)

Caplan, S. E., Preference for Online Social Interaction A Theory of Problematic Internet Use and Psychosocial Well-Being. Communication Research, 30(6), 625-648 (2003)

Carbonell, X., Fúster, H., Chamarro, A., y Oberst, U., Adicción a Internet y móvil: una revisión de estudios empíricos españoles. Papeles del Psicólogo, 33(2), 82-89 (2012)

Castellana, M., Sánchez-Carbonell, X., Graner, C. y Beranuy, M., El adolescente ante las Tecnologías de la Información y la Comunicación: Internet, móvil y videojuegos. Papeles del Psicólogo, 28(3), 196-204 (2007)

Chung, J. E., Social interaction in online support groups: Preference for online social interaction over offline social interaction. Computers in Human Behavior, 29(4), 1408-1414 (2013)

Cruces, S. J., Guil, R., Sánchez N. y Pereira, J. A., Consumo de nuevas tecnologías y factores de personalidad en estudiantes universitarios. Revista de Comunicación y Ciudadanía Digital, 5(2), 203-228 (2016)

Echeburría, E. y De Corral, P., Adicción a las nuevas tecnologías y a las redes sociales en jóvenes: Un nuevo reto. Adicciones, 22(2), 91-96 (2010)

Fundación Pfizer, La Juventud y las Redes Sociales en Internet. Recuperado de: https://goo.gl/cbrCSn. Acceso: 1 de marzo de 2014 (2009)

Fundación Telefónica., La Sociedad de la Información en España 2016. Ariel, Madrid, España (2016)

Garaigordobil, M., Prevalencia y consecuencias del cyberbullying: Una revisión. International Journal of Psychology and Psychological Therapy, 11(2), 233-254 (2011)

García, J. A., Terol, M. C., Nieto, M., Lledó, A., Sánchez, S., Martín-Aragón, M. y Sitges, E., Uso y abuso de internet en jóvenes universitarios. Adicciones, 20(2), 131-142 (2008)

Garmendia, M., Garitaonandia, C., Martínez G. y Casado. M. A., Riesgos y seguridad en Internet: Los menores en el contexto europeo. EU Kids Online, Bilbao, España (2011)

Giménez, A.M., Maquilón, J.J. y Arnáiz, P., Usos problemáticos y agresivos de las TIC por parte de adolescentes implicados en cyberbulling. Revista de Investigación Educativa, 33(2), 335-351 (2015)

González, N. y Estévez, A., El apoyo social percibido moderador entre el uso problemático de internet y la sintomatología depresiva en jóvenes adultos. Health anda Addictions, 17(1), 53-62 (2017)

Gracia, M. De, Vigo, M., Fernández, M. J. y Marcó, M., Problemas conductuales relacionados con el uso de Internet: Un estudio exploratorio. Anales de Psicología, 18(2), 273-292 (2002) 
Kaess, M., Durkee, T., Brunner, R., Carli, V., Parzer, P., Wasserman, C. y Wasserman, D., Pathological Internet use among European adolescents: psychopathology and self-destructive behaviours. European Child \& Adolescent Psychiatry, 23, 1093-1102 (2014)

Marciales, G. P. y Cabra, F., Internet y pánico moral: Revisión de la investigación sobre la interacción de niños y jóvenes con los nuevos medios. Universitas Psycholoógica, 10(3), 855-865 (2011)

Muñoz-Rivas, M. J., Fernández, L., y Gámez-Guadix, M., Analysis of the Indicators of Pathological Internet Use in Spanish University Students. Spanish Journal of Psychology, 13(2), 697-707 (2010)

Romero, F., Carrió, M. L. y Yang, Q., Hábitos de consumo TIC de los estudiantes universitarios. Estudio comparativo entre China y España. Aprendizajes plurilingües y literarios. Nuevos enfoques didácticos. Publicaciones de la Universidad de Alicante, Alicante, España (2016)

Ruiz, F. J. y Belmonte, A. M., Los jóvenes como usuarios de aplicaciones de marca en dispositivos móviles. Comunicar, 43(22), 73-81 (2014)

Ruiz, C., Perfil de uso del teléfono móvil e internet en una muestra de universitarios españoles: ¿Usan o abusan? Bordón, 68(3), 131-145 (2016)

Ruiz-Palmero, J., Sánchez-Rodríguez, J. y Trujillo-Torres, J. M., Utilización de Internet y dependencia a teléfonos móviles en adolescentes. Revista Latinoamericana de Ciencias Sociales, Niñez y Juventud, 14(2), 1357-1369 (2016)

Torres, J. C., Duart, J. M., Gómez, H. F., Marín I. y Segarra, V., Uso de internet y éxito académico en estudiantes universitarios. Comunicar, 48(24), 61-70 (2016)

Wang, C. S., Wu, J. Y., Chang, W. C., y Chuang, S. P., Cognitive functioning correlates of self-esteem and health locus of control in schizophrenia. Neuropsychiatric Disease and Treatment, 9, 1647-1654 (2013)

Winocur, R., Internet en la vida cotidiana de los jóvenes. Revista mexicana de sociología, 68(3), 551-580 (2006)

Yang, S. C. y Tung, C., Comparison of internet addicts and non-addicts in Taiwanese high school. Computers in Human Behavior, 23, 79-96 (2007)

Young, K. S., Internet Addiction: The Emergence of a New Clinical Disorder. CyberPsychology \& Behavior, 1(3), 237-244 (1998) 